OPEN ACCESS

International Journal of

Environmental Research and

Public Health

ISSN 1660-4601

www.mdpi.com/journal/ijerph

Article

\title{
Treatment of Ammonia Nitrogen Wastewater in Low Concentration by Two-Stage Ozonization
}

\author{
Xianping Luo ${ }^{1,2,3, *}$, Qun Yan ${ }^{1,3}$, Chunying Wang ${ }^{1,2,3}$, Caigui Luo ${ }^{1,3}$, Nana Zhou ${ }^{1,3}$ \\ and Chensheng Jian 1,3
}

1 School of Resuorces and Environmental Engieering, Jiangxi University of Science and Technology, Ganzhou 341000, Jiangxi, China; E-Mails: yanqun8219893@163.com (Q.Y.); cywang@jxust.edu.cn (C.W.); andk24@163.com (C.L.); hdongxue@163.com (N.Z.); gctao@163.com (C.J.)

2 Western Mining Co., Ltd., Xining 810006, Qinghai, China

3 Jiangxi Key Laboratory of Mining \& Metallurgy Environmental Pollution Control, Jiangxi University of Science and Technology, Ganzhou 341000, Jiangxi, China

* Author to whom correspondence should be addressed; E-Mail: 1xp9491@163.com; Tel.: +86-797-8312-706.

Academic Editor: Miklas Scholz

Received: 9 July 2015 / Accepted: 18 September 2015 / Published: 23 September 2015

\begin{abstract}
Ammonia nitrogen wastewater (about $100 \mathrm{mg} / \mathrm{L}$ ) was treated by two-stage ozone oxidation method. The effects of ozone flow rate and initial $\mathrm{pH}$ on ammonia removal were studied, and the mechanism of ammonia nitrogen removal by ozone oxidation was discussed. After the primary stage of ozone oxidation, the ammonia removal efficiency reached $59.32 \%$ and $\mathrm{pH}$ decreased to 6.63 under conditions of $1 \mathrm{~L} / \mathrm{min}$ ozone flow rate and initial $\mathrm{pH}$ 11. Then, the removal efficiency could be over $85 \%$ (the left ammonia concentration was lower than $15 \mathrm{mg} / \mathrm{L}$ ) after the second stage, which means the wastewater could have met the national discharge standards of China. Besides, the mechanism of ammonia removal by ozone oxidation was proposed by detecting the products of the oxidation: ozone oxidation directly and $\cdot \mathrm{OH}$ oxidation; ammonia was mainly transformed into $\mathrm{NO}_{3}{ }^{-}-\mathrm{N}$, less into $\mathrm{NO}_{2}{ }^{-}-\mathrm{N}$, not into $\mathrm{N}_{2}$.
\end{abstract}

Keywords: ammonia nitrogen wastewater; ozone oxidation; mechanism 


\section{Introduction}

Wastewater generated during rare earth production is radioactive, ammonia-containing, fluoride-containing, acid or alkaline [1]. In recent years, the long-term mining of rare earth ore in southern Jiangxi, China, produced large amounts of ammonia nitrogen wastewater in low concentrations. The wastewater that is rich in ammonia nitrogen would inhibit the natural nitrification, cause water hypoxia, result in fish poisoning, decrease the water purification capacity, and finally do great harm to the water environment [2]. $\mathrm{NH}_{3}$, as a neutral molecule, is able to diffuse across the epithelial membranes of aquatic organisms much more readily than the charged ammonia ion. It was reported that, ammonia could block oxygen transfer in the gills of fish. Fish suffering from ammonia poisoning appear sluggish, and come to the surface of water gasping for air. In marine environments, the safe level of ammonia is below $1 \mathrm{mg} / \mathrm{L}$ [3]. In China, the primary standard of ammonia nitrogen in wastewater is less than $15 \mathrm{mg} / \mathrm{L}$ and the secondary standard is less than $50 \mathrm{mg} / \mathrm{L}$ (Integrated wastewater discharge standard (GB 8978-1996)). The methods of chemical precipitation, blow-off, and adsorption are commonly used for the treatment of ammonia nitrogen wastewater at low concentration. Chemical precipitation method intends to reduce the water solubility of ammonia nitrogen by the formation of indissoluble salt; blow-off method is typically used $\mathrm{NaOH}$ to adjust $\mathrm{pH}$ to basic of wastewater and ammonia nitrogen would exist in the form of free ammonia $\left(\mathrm{NH}_{3}\right)$. Then, ammonia nitrogen would escape from aqueous solution to the atmosphere. Besides, Biological nitrification as the most reliable method for the removal of ammonia has been established widely. However, biological nitrification beds are subject to great fluctuations in efficiency, as nitrifying bacteria in biofilter beds are sensitive to environmental perturbations and changes in operating conditions, which often implicate color, odor and flavor problems and moreover impair biofilter function [4]. All methods have their own characteristics, but each has its limitations, or has different levels of equipment investment, high operating costs, secondary pollution, and other shortcomings [5-9]. Therefore, it is necessary and urgent to seek efficient, practical, low concentration ammonia removal methods.

Ozone is a strong oxidizer, especially when there coexist a lot of $\mathrm{OH}^{-}, \mathrm{H}_{2} \mathrm{O}_{2} / \mathrm{HO}^{-}, \mathrm{Fe}^{2+}, \mathrm{UV}$ and other free radical activators or accelerators [10,11]. Under the action of excited agent radicals and the accelerator, the ozone would induce large amounts of hydroxyl radicals $(\cdot \mathrm{OH})$ in the reaction system, which would lead to chain reactions and then produce more reactive radicals. Besides, ozone is easy to operate. So, ozone treatment is one of the most common processes utilized in industry: decolorization of wastewater containing direct dye (Sirius Blue SBRR) by ozonization was studied in an attempt to abate pollution caused by textile dyeing houses and dye-producing plants [12]; domeno reported that ozonization was one of the most efficient treatment of volatile organic compounds and odors from gaseous emissions [13]; ozone could be used to remove metal Tin from ITO-scrap [14]. Thus, ozone oxidation technology is favored by researchers in the treatment of various pollutants. Ammonia nitrogen was also treated by ozonization [15-17]. As other oxidants [6,18], ozone could convert highly toxic ammonia and nitrite to nitrate with low toxicity [15].

In order to meet the discharge standard of China, the ammonia nitrogen wastewater at a medium or low concentration of about $100 \mathrm{mg} / \mathrm{L}$ was treated by two-stage ozone oxidation method in this study. Effects of ozone flow rate, initial $\mathrm{pH}$ of reaction solution, and reaction time on the ammonia nitrogen 
removal were investigated by ozone wet oxidation. The transformation process of ammonia nitrogen was analyzed to deduce the mechanism of ammonia nitrogen removal.

\section{Experimental Section}

\subsection{Experimental Reagents and Apparatus}

Ammonium chloride, mercuric iodide, potassium persulfate, and hydrochloric acid were of analytical grade and used without any further purification; ozone was provided by LH-YT-10G ozone generator (Tongfang Environment Co., Ltd., Beijing, China); $\mathrm{pH}$ and absorbance values were determined by REX PHS-3C pH meter (Shanghai INESA Scientific Instrument Co., Ltd., Shanghai, China) and SP-1920 UV spectrophotometer (Unico (Shanghai) Instrument Co., Ltd., Shanghai, China) respectively. The experimental apparatus is a cylindrical reactor made of transparent glass, and the oxidation system comprises several operation units as shown in Figure 1.

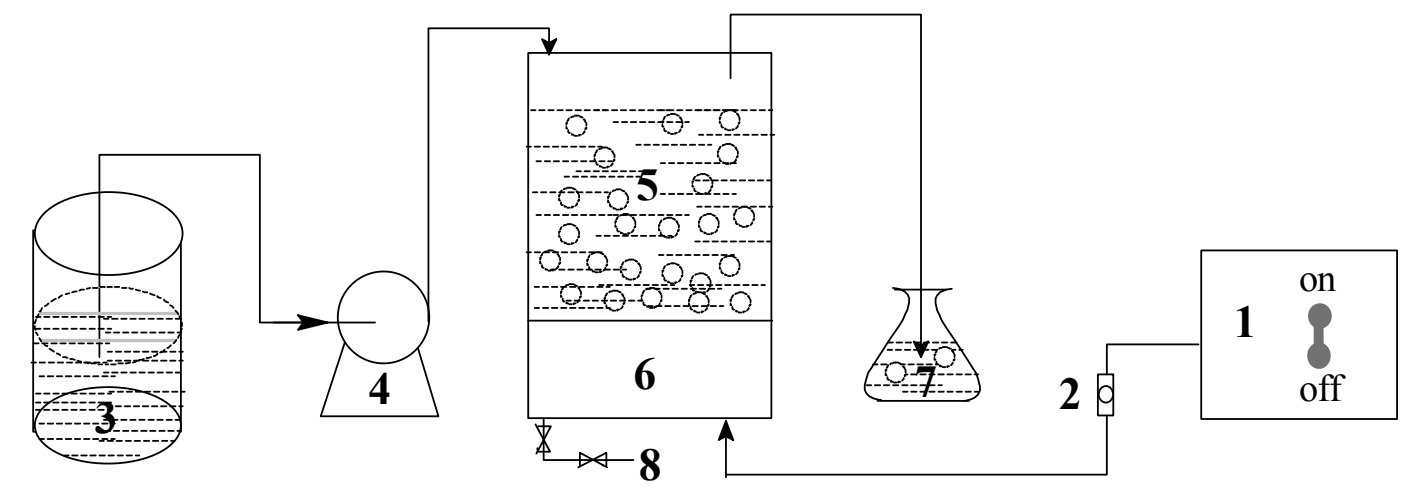

Figure 1. The flowchart of experimental apparatus. (1) Ozone generator; (2) Gas flowmeter; (3) Raw water tank; (4) Constant flow pump; (5) Reaction column; (6) Air distribution plate; (7) Tail gas absorption bottle; (8) Outlet.

\subsection{Analysis Method}

Ammonia-containing wastewater $(100 \pm 10 \mathrm{mg} / \mathrm{L}$, pH 6-6.2) was prepared by ammonia chloride. At room temperature (about $25{ }^{\circ} \mathrm{C}$ ), $500 \mathrm{~mL}$ of water sample was added into the reactor after the adjustment of $\mathrm{pH}$, then ozone was pumped in. The reaction solution was sampled every 20 min to analyze the changes of $\mathrm{pH}$ values, concentrations of ammonia nitrogen $\left(\mathrm{NH}_{4}{ }^{+} \mathrm{N}\right)$, nitrite nitrogen $\left(\mathrm{NO}_{2}{ }^{-} \mathrm{N}\right)$, nitrate nitrogen $\left(\mathrm{NO}_{3}{ }^{-}-\mathrm{N}\right)$, and total nitrogen $(\mathrm{TN}) \cdot \mathrm{pH}$ value was measured by $\mathrm{pH}$ meter, and the concentrations of chemicals above were measured by spectrophotometry methods as shown in Table 1. Ozone flow rate, reaction time, and $\mathrm{pH}$ values were the main effects considered in the experiment of ammonia removal by ozone wet oxidation. The removal efficiency $(R)$ was calculated by Equation (1) as follows:

$$
R=\left(C_{0}-C\right) / C_{0} \times 100 \%
$$

where $C_{0}$ is the initial concentration of ammonia nitrogen and $C$ is the concentration at reaction time $t$ (min). 
Table 1. Methods of determination.

\begin{tabular}{lccc}
\hline Project Name & Determination & Standard Number & Reference \\
\hline Ammonia nitrogen & $\begin{array}{c}\text { Nessler's reagent } \\
\text { spectrophotometry }\end{array}$ & HJ 535-2009 & {$[19]$} \\
\hline Nitrite & $\begin{array}{c}\text { N-(1-naphthyl)-ethylenediamine } \\
\text { spectrophotometry }\end{array}$ & GB 7493-87 & {$[20]$} \\
\hline Nitrate & $\begin{array}{c}\text { Phenol disulfonic acid } \\
\text { spectrophotometry }\end{array}$ & GB 7480-87 & {$[21]$} \\
\hline Total nitrogen & $\begin{array}{c}\text { Alkaline potassium persulfate } \\
\text { digestion spectrophotometry }\end{array}$ & HJ 636-2012 & {$[22]$} \\
\hline
\end{tabular}

There are two processes of ammonia removal by ozone wet oxidation including oxidation by ozone and ammonia nitrogen stripping by ozone flow. An air stripping experiment was set as a blank experiment to simulate the stripping removal of ammonia by ozone.

\section{Results and Discussion}

\subsection{Blank Stripping}

Air flow rate in the stripping experiment was over $3 \mathrm{~L} / \mathrm{min}$ and the $\mathrm{pH}$ of $\mathrm{NH}_{4}{ }^{+}-\mathrm{N}$ solution was adjusted to 11 . The curves of ammonia concentration and ammonia removal efficiency versus stripping time were seen in Figure 2. Ammonia nitrogen removal efficiency increased with the prolonging of time until $100 \mathrm{~min}$, and there was no significant change to $120 \mathrm{~min}$. In addition, the maximum removal efficiency was only $12.8 \%$ by air stripping with the flow rate over $3 \mathrm{~L} / \mathrm{min}$. Ammonia removal efficiency in ozone oxidation system should be smaller than $12.8 \%$ because ozone flow rate would be set smaller than $3 \mathrm{~L} / \mathrm{min}$.

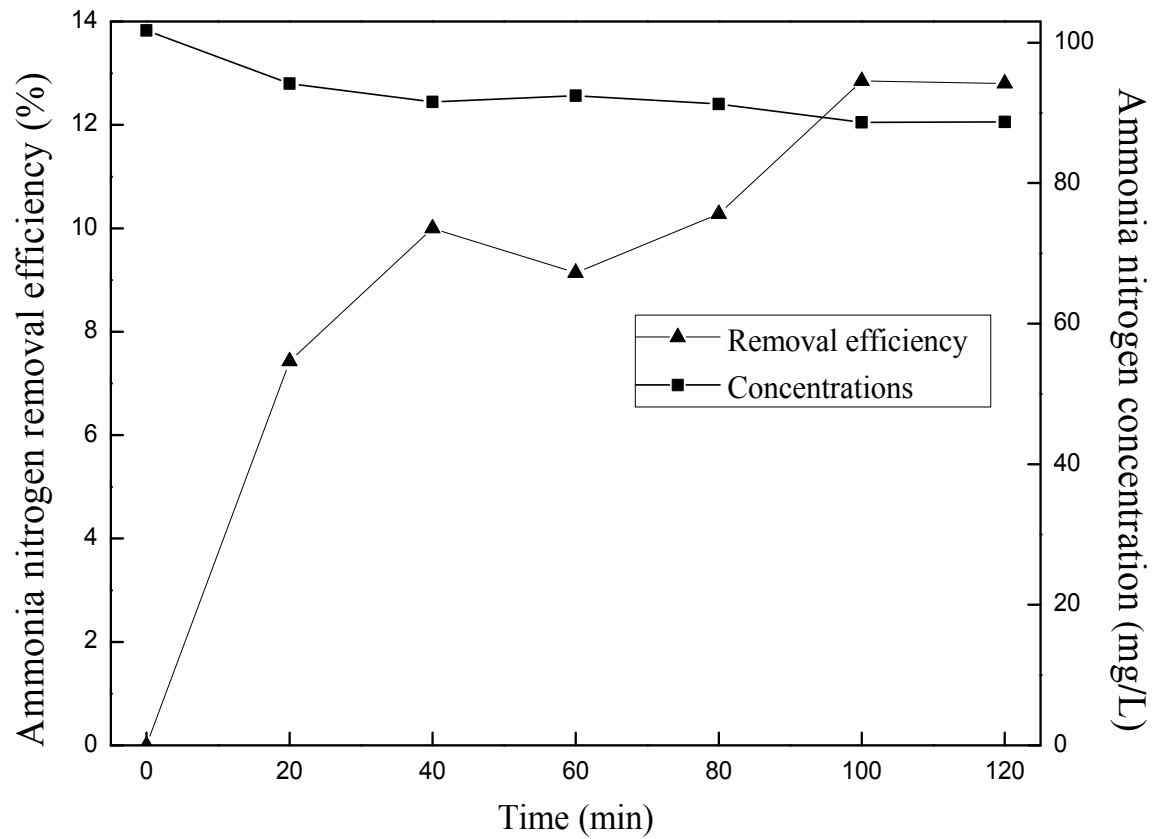

Figure 2. Curves of blank stripping over $3 \mathrm{~L} / \mathrm{min}$ air stream. 


\subsection{Effects of Ozone Concentrations on Ammonia Removal}

First, the outlet of ozone generator was inserted directly into an exhaust absorption flask containing potassium iodide solution. Then, the ozone was transferred into another exhaust gas absorption flask as same as the first one when the ozone pressure, current, and flow rate were stable. After a certain period, the power was turned off and the residual potassium iodide was titrated by the sodium thiosulfate standard solution [23]. The concentration of ozone was calculated by Equation (2), and the relationship between the ozone concentration and the flow rate is shown in Table 2.

$$
\mathrm{CO}_{3}=A_{\mathrm{Na}} \times B \times 24.00 / V_{0}(\mathrm{mg} / \mathrm{L})
$$

where $\mathrm{Co}_{3}$ is ozone concentration, $\mathrm{mg} / \mathrm{L} ; A_{\mathrm{Na}}$ is the consumption of sodium thiosulfate standard solution, $\mathrm{mL} ; B$ is the concentration of sodium thiosulfate standard solution, mol/L; $V_{0}$ is the volume of ozone gas, L.

Table 2. The relationship between ozone concentration and flow rate.

\begin{tabular}{ccccccc}
\hline Ozone Flow Rate (L/min) & 0 & 0.3 & 0.5 & 0.8 & 1.0 & 1.3 \\
Ozone Concentration (mg/L) & 0 & 25.83 & 30.24 & 51 & 58.14 & 71.82 \\
\hline
\end{tabular}

Experiments were performed with $\mathrm{pH} 10$ of the initial solution in the system at different ozone flow rates $(0.3,0.5,0.8,1.0,1.3$ and $1.5 \mathrm{~L} / \mathrm{min})$. The effects of different ozone flow rates on the ammonia removal efficiency and ammonia removal rate are shown in Figure 3.
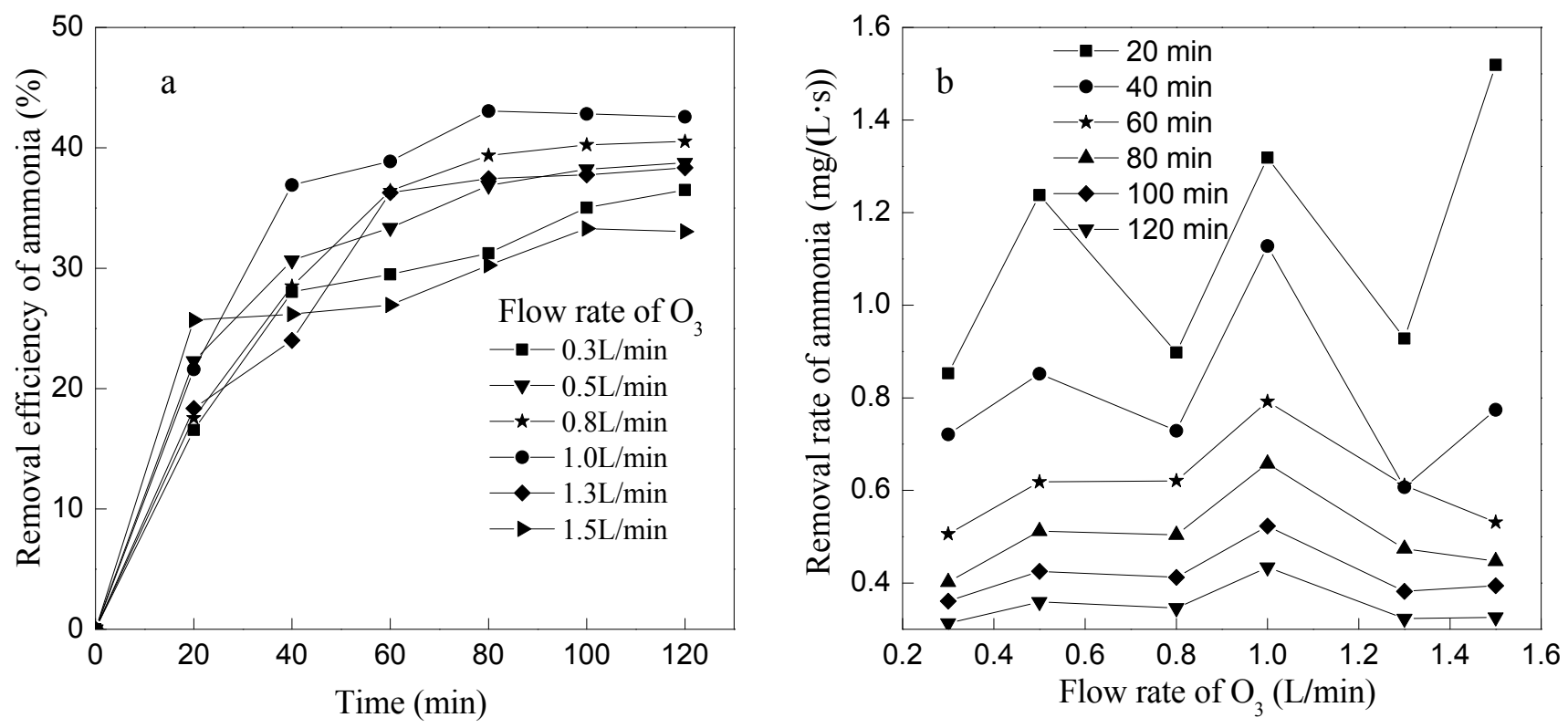

Figure 3. Effect of ozone flow rate on ammonia removal. (a) The effect of ozone flow rate on removal efficiency of ammonia; (b) The effect of ozone flow rate on removal rate of ammonia.

As seen from Figure 3a, the removal efficiency of ammonia nitrogen all increased gradually versus time at different ozone flow rates till $100 \mathrm{~min}$. The removal efficiency increased with the increase of ozone flow rate when the ozone flow rate was less than $1 \mathrm{~L} / \mathrm{min}$. However, the ammonia removal efficiency decreased with the increase of ozone flow rate when ozone flow rate was more than $1 \mathrm{~L} / \mathrm{min}$. 
So, the optimum ozone flow rate of ammonia removal by ozone oxidation was $1 \mathrm{~L} / \mathrm{min}$ in this study. From another point of view, as seen in Figure 3b, the ammonia removal rate decreased with the increase of ozone flow rate when ozone flow rate $\geq 1 \mathrm{~L} / \mathrm{min}$. The reason for this phenomenon may be that greater ozone flow could not support enough time for the contact between ozone molecules and $\mathrm{OH}^{-}$, which would lead to the slow generation rate of $\cdot \mathrm{OH}$, as showed in Equations (3) and (4); besides, the excessive flow would go against the direct ammonia oxidation by ozone. Ammonia removal efficiency reached $43.06 \%$ and $\mathrm{pH}$ reduced to 7.1 under the conditions of $1 \mathrm{~L} / \mathrm{min}$ ozone flow rate and 80 min reaction time.

$$
\begin{gathered}
\mathrm{O}_{3}+\mathrm{OH}^{-} \rightarrow \mathrm{HO}_{2}^{-}+\mathrm{O}_{2} \\
\mathrm{O}_{3}+\mathrm{HO}_{2}^{-} \rightarrow \cdot \mathrm{OH}+\mathrm{O}_{2}^{-}+\mathrm{O}_{2}
\end{gathered}
$$

$\mathrm{pH}$ value of wastewater decreased gradually with the increasing of the removal reaction (Figure 4a) and the decreased rate of $\mathrm{pH}$ increased first and then decreased with the ozone flow increased (Figure 4b). The reason of $\mathrm{pH}$ value decreased was mainly due to the continuous production of $\mathrm{H}^{+}$during the oxidation process of ammonia and the consumption of $\mathrm{OH}^{-}$by $\mathrm{O}_{3}$. There was no big difference to the changes of $\mathrm{pH}$ value among $0.8,1,1.3$, and $1.5 \mathrm{~L} / \mathrm{min}$ of ozone flow rate, but there was the lowest $\mathrm{pH}$ value when ozone flow rate was $1.0 \mathrm{~L} / \mathrm{min}$ after $120 \mathrm{~min}$. As mentioned above, $\mathrm{OH}^{-}$was induced to $\cdot \mathrm{OH}$ in the process of ozone wet oxidation, and it was unfavorable for the $\cdot \mathrm{OH}$ production if the ozone flow rate was too fast or too slow. Therein, the ammonia removal efficiency and the production $\mathrm{H}^{+}$were all decreased when the ozone flow rate was less or more than $1.0 \mathrm{~L} / \mathrm{min}$.
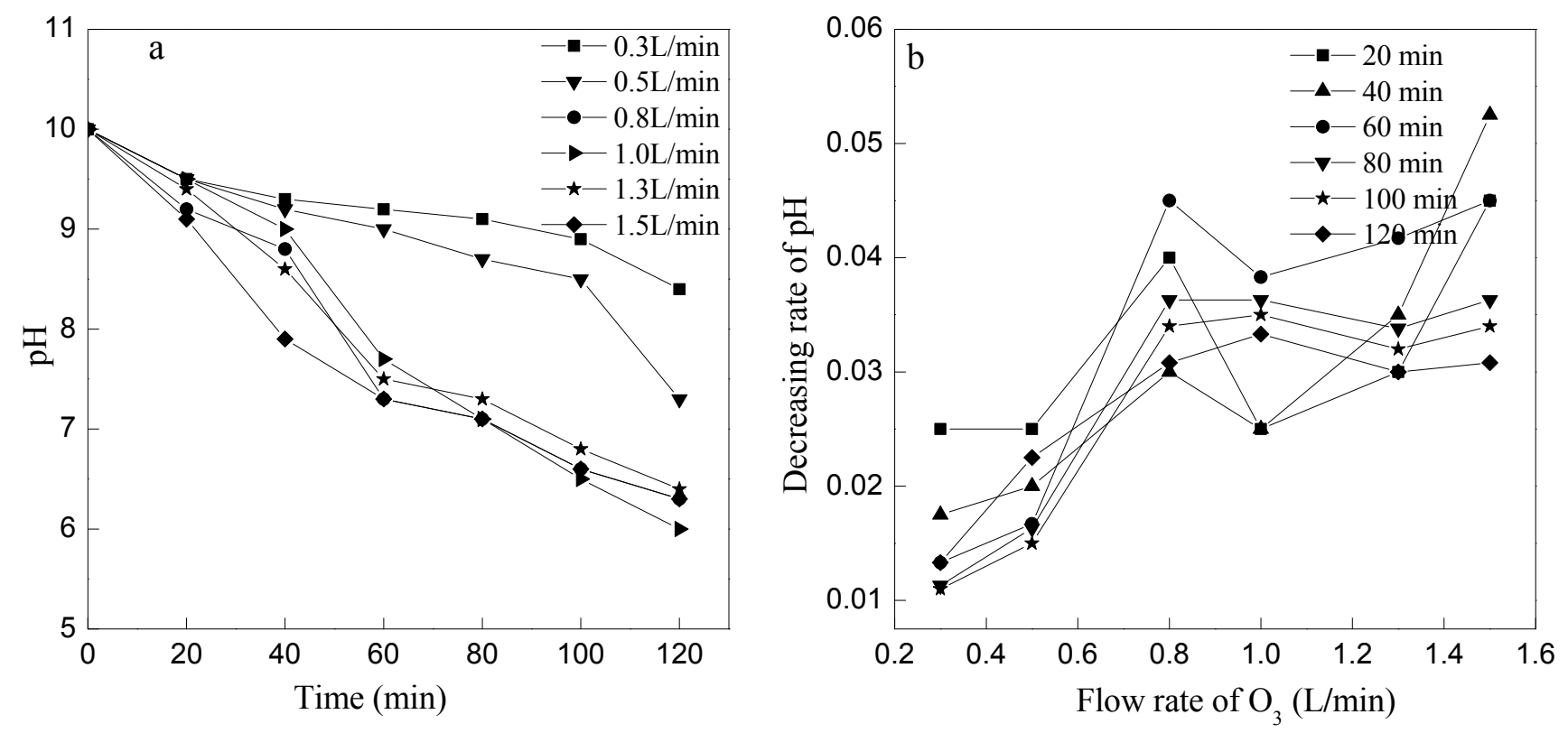

Figure 4. Variation of $\mathrm{pH}$ versus reaction time at different ozone flow rates. (a) The changes of $\mathrm{pH}$ at different ozone flow rate; (b) The decreasing rate of $\mathrm{pH}$ at different ozone flow rate. 


\subsection{Effect of Initial pH on Ammonia Removal by Ozone Oxidation}

To investigate the effect of initial $\mathrm{pH}$ on ammonia removal by ozone oxidation, a series of experiments were designed with different initial $\mathrm{pH}$ values $(8,9,10,11$, and 12$)$ at the ozone flow rate of $1 \mathrm{~L} / \mathrm{min}$. The result is shown in Figures 5 and 6.
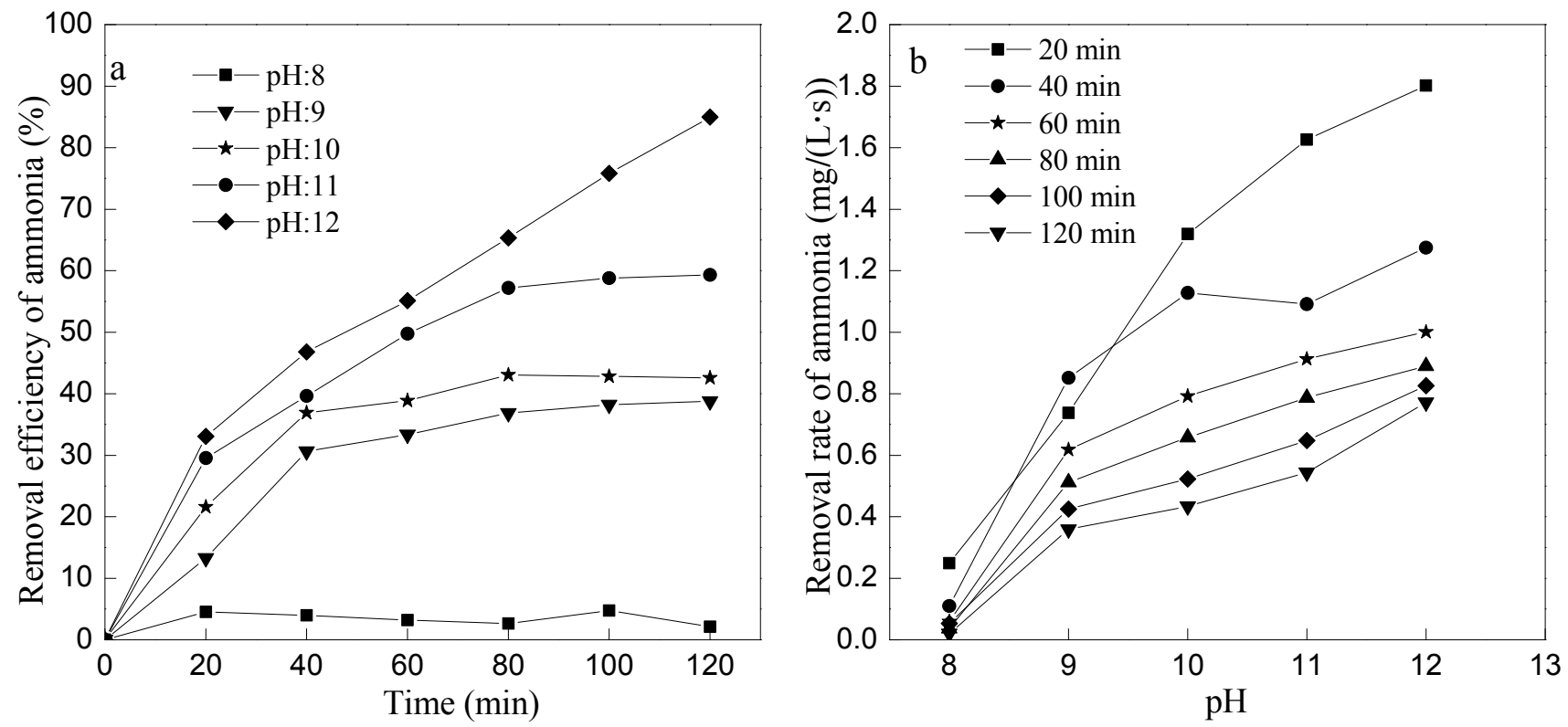

Figure 5. Effect of initial $\mathrm{pH}$ on oxidation of ammonia. (a) The effect of initial $\mathrm{pH}$ on removal efficiency of ammonia; (b) The effect of initial $\mathrm{pH}$ on removal rate of ammonia.
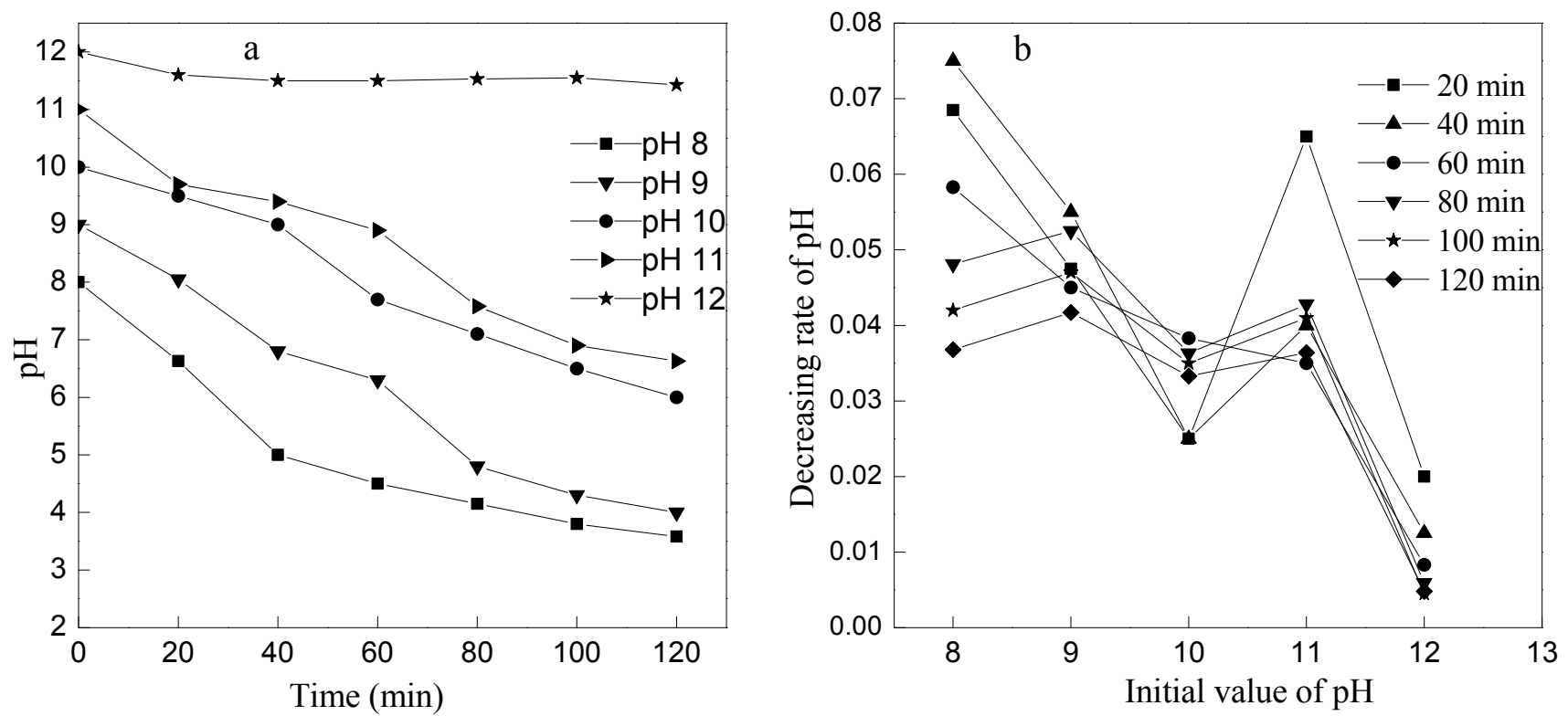

Figure 6. Variation of $\mathrm{pH}$ with reaction time at different initial $\mathrm{pH}$. (a) The changes of $\mathrm{pH}$ at different initial $\mathrm{pH}$; (b) The decreasing rate of $\mathrm{pH}$ at different initial $\mathrm{pH}$.

The initial $\mathrm{pH}$ value of the reaction solution has important effect on the ammonia removal by ozone oxidation. The higher of the $\mathrm{pH}$ value, the larger of the ammonia nitrogen removal efficiency. There was 
almost no removal of ammonia at initial $\mathrm{pH} 8$ while the removal efficiency reached $84.97 \%$ at initial pH 12 after $120 \mathrm{~min}$.

It is observed from Figure 6 that $\mathrm{pH}$ value of the wastewater kept reducing with the reaction time prolonged, and, the smaller of initial $\mathrm{pH}$ value, the greater of changing $\mathrm{pH}$ rate. However, the $\mathrm{pH}$ decreased slowly when initial $\mathrm{pH}$ was 12 , which reduced to $\mathrm{pH} 11.43$ at the reaction time of $120 \mathrm{~min}$. If the initial $\mathrm{pH}$ was adjusted to 12 , it would require large amount of acid to neutralize the excessive alkalis ( $\mathrm{pH}$ value is 11.43) in order to meet the discharge standard. The efficiency of ammonia removal reached $57.20 \%$ and $\mathrm{pH}$ value decreased to 7.58 after $80 \mathrm{~min}$ at initial $\mathrm{pH} \mathrm{11,} \mathrm{which} \mathrm{was} \mathrm{not} \mathrm{only}$ higher than the efficiency at initial $\mathrm{pH} 10$ by14\%, but also consumed much less acid than that an initial $\mathrm{pH}$ value of 12 . So, $\mathrm{pH}$ value is 11 was chose to be the optimum initial $\mathrm{pH}$ value at ozone flow rate $1 \mathrm{~L} / \mathrm{min}$.

\subsection{Mechanism Analysis}

There are two forms of ammonia nitrogen in water solution, free ammonia $\left(\mathrm{NH}_{3}\right)$ and ammonium ion $\left(\mathrm{NH}_{4}^{+}\right)$, which are reversible, as seen in Equation (5). The composition ratio of $\mathrm{NH}_{3}$ to $\mathrm{NH}_{4}^{+}$depends on the $\mathrm{pH}$ value of water and the water temperature. The higher $\mathrm{pH}$ value, the higher proportion of $\mathrm{NH}_{3}$; conversely, the ammonium ion proportion is higher at a lower $\mathrm{pH}$ value. At $\mathrm{pH} 7$ of the waste water, ammonia nitrogen exists mainly in the form of $\mathrm{NH}_{4}{ }^{+}$, while more than $90 \%$ [24] is free ammonia when the $\mathrm{pH}$ is over 11. In addition, during the ozone oxidation process of ammonia, the reaction rate constant of molecular ozone and ammonia was $20 \mathrm{~L} \cdot(\mathrm{mol} \cdot \mathrm{s})^{-1}$, and the reaction rate constant of molecular ozone and ammonium ion is only $1 \mathrm{~L} \cdot(\mathrm{mol} \cdot \mathrm{s})^{-1}[25]$. The capacity of oxidative degradation of $\mathrm{O}_{3}$ on ammonia nitrogen increases with the improvement of the $\mathrm{pH}$ value. Besides, high $\mathrm{pH}$ could accelerate the decomposition of $\mathrm{O}_{3}$, and then induce the generation of $\cdot \mathrm{OH}$, which has strong oxidative ability. So, the degradation of ammonia nitrogen by ozone wet oxidation includes both $\mathrm{O}_{3}$ molecular oxidation directly (Equations (6)-(10)) and $\cdot \mathrm{OH}$ oxidation reaction (Equations (3), (4), and (11)-(13)) [26]. Ozone oxidation predominates the reaction at low $\mathrm{pH}$, while $\cdot \mathrm{OH}$ oxidation is the main reaction at high $\mathrm{pH}$, and $\cdot \mathrm{OH}$ oxidation has the faster reaction rate [27,28]. As discussed in Sections 3.2 and 3.3 of this study, the ozone flow rate would affect the contacting time of reaction between ozone molecules or $\cdot \mathrm{OH}$ and free ammonia, so ozone flow rate of $1 \mathrm{~L} / \mathrm{min}$ and initial $\mathrm{pH}$ of 11 were chosen as the optimum conditions in the process of ammonia nitrogen removal by ozone oxidation.

$$
\begin{gathered}
\mathrm{NH}_{4}^{+}+\mathrm{OH}^{-} \leftrightharpoons \mathrm{NH}_{3}+\mathrm{H}_{2} \mathrm{O} \\
3 \mathrm{O}_{3}+\mathrm{NH}_{4}^{+} \rightarrow \mathrm{NO}_{2}{ }^{-}+2 \mathrm{H}^{+}+\mathrm{H}_{2} \mathrm{O}+3 \mathrm{O}_{2} \\
\mathrm{NO}_{2}{ }^{-}+\mathrm{O}_{3} \rightarrow \mathrm{NO}_{3}^{-}+\mathrm{O}_{2} \\
4 \mathrm{O}_{3}+\mathrm{NH}_{4}^{+} \rightarrow \mathrm{NO}_{3}{ }^{-}+2 \mathrm{H}^{+}+\mathrm{H}_{2} \mathrm{O}+4 \mathrm{O}_{2} \\
3 \mathrm{O}_{3}+\mathrm{NH}_{3} \rightarrow \mathrm{NO}_{2}{ }^{-}+\mathrm{H}^{+}+\mathrm{H}_{2} \mathrm{O}+3 \mathrm{O}_{2} \\
4 \mathrm{O}_{3}+3 \mathrm{NH}_{3} \rightarrow \mathrm{NO}_{3}^{-}+\mathrm{H}^{+}+\mathrm{H}_{2} \mathrm{O}+4 \mathrm{O}_{2} \\
6 \cdot \mathrm{OH}+\mathrm{NH}_{3} \rightarrow \mathrm{NO}_{2}^{-}+\mathrm{H}^{+}+4 \mathrm{H}_{2} \mathrm{O} \\
\mathrm{NO}_{2}^{-}+2 \cdot \mathrm{OH} \rightarrow \mathrm{NO}_{3}^{-}+\mathrm{H}_{2} \mathrm{O} \\
\mathrm{NH}_{3}+8 \cdot \mathrm{OH} \rightarrow \mathrm{NO}_{3}{ }^{-}+\mathrm{H}^{+}+5 \mathrm{H}_{2} \mathrm{O}
\end{gathered}
$$


The products of ammonia nitrogen degradation could be $\mathrm{NO}_{3}{ }^{-}$and $\mathrm{NO}_{2}^{-}$by above equations. In order to confirm the final product of ammonia nitrogen oxidation by ozone, concentrations of $\mathrm{NO}_{3}{ }^{-}$, $\mathrm{NO}_{2}{ }^{-}$and $\mathrm{TN}$ were measured at the ozone flow rate of $1 \mathrm{~L} / \mathrm{min}$ and $\mathrm{pH} 10, \mathrm{pH} 11$, respectively.

As seen from Figure 7, content of $\mathrm{NO}_{3}{ }^{-}-\mathrm{N}$ increases with the degradation of ammonia nitrogen, and the $\mathrm{NO}_{3}{ }^{-}-\mathrm{N}$ concentration also tends to be smooth while the concentration of ammonia nitrogen tends to be stable. Concentration of nitrite had been very low, less than $1 \mathrm{mg} / \mathrm{L}$, due to the instability of nitrite, which is easily oxidized to nitrate.
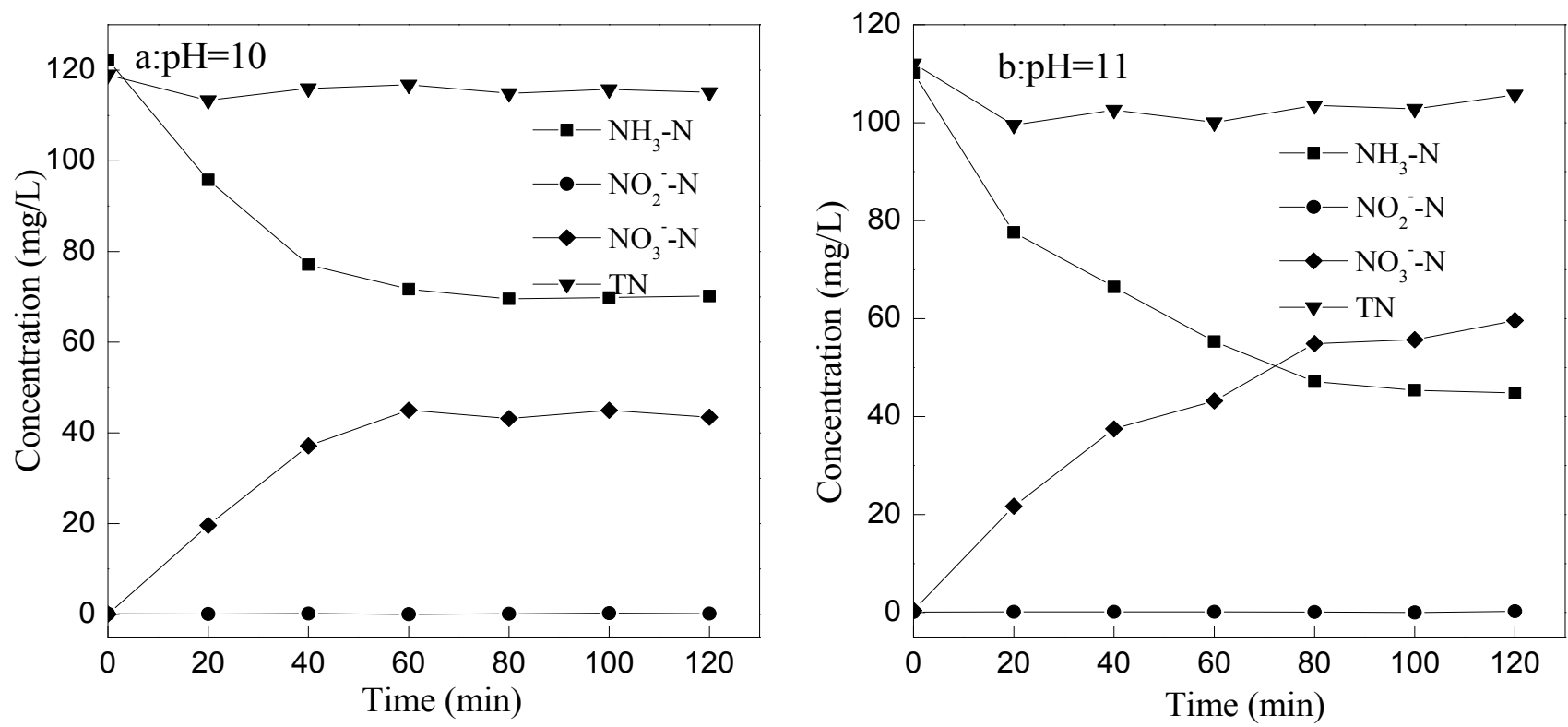

Figure 7. The concentration changes of $\mathrm{NH}_{4}{ }^{+}-\mathrm{N}, \mathrm{TN}, \mathrm{NO}_{3}-\mathrm{N}$, and $\mathrm{NO}^{2-}-\mathrm{N}$ with time. (a) At pH 10; (b) At pH 11.

At the beginning of reaction, TN decreased slightly. After $40 \mathrm{~min}$ of the reaction, TN increased slightly, and this might be due to the external nitrogen in the atmosphere. Therefore, the TN content had little change through the whole process, which means that the ammonia removal effect of stripping is less than the oxidation of ozone. In another word, $\mathrm{NH}_{4}^{+}-\mathrm{N}, \mathrm{NO}_{3}-\mathrm{N}, \mathrm{NO}_{2}-\mathrm{N}$, and $\mathrm{TN}$ are in dynamic equilibrium, and ammonia nitrogen is difficult to convert to $\mathrm{N}_{2}$ in the ozone oxidation process.

\section{The Second Stage Treatment of Ammonia Nitrogen Wastewater}

The ammonia removal efficiency reaches $59.32 \%$ by the primary treatment of ozone oxidation at the conditions of $1 \mathrm{~L} / \mathrm{min}$ ozone flow rate, initial $\mathrm{pH} \mathrm{11}$, and $120 \mathrm{~min}$ of the reaction. However, it still does not meet the primary discharge standard of China. Therefore, two-stage treatment of ammonia nitrogen wastewater was introduced: the wastewater treated by the primary treatment was treated again by ozone wet oxidation with the same ozone flow rate of $1 \mathrm{~L} / \mathrm{min}$, and $\mathrm{pH}$ value was regulated to 11 again.

After being treated by the second stage of ozone oxidation, the ammonia removal efficiency reached more than $85 \%$ and ammonia concentration was below $15 \mathrm{mg} / \mathrm{L}$ (Figure 8), which meets the national discharge standards of China. 


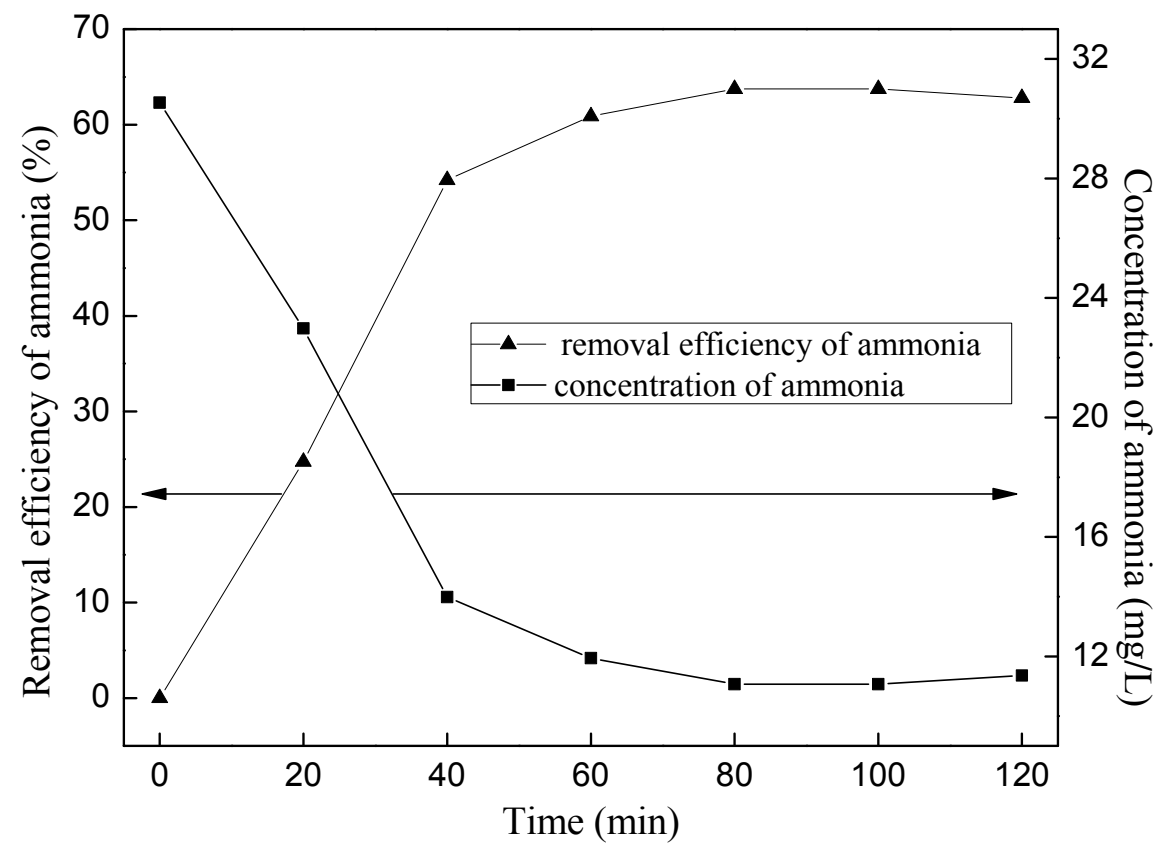

Figure 8. The removal of ammonia by two stages of ozone oxidation.

\section{Conclusions}

By the two-stage treatment of ozone wet oxidation, ammonia nitrogen wastewater with the original concentration of $100 \pm 10 \mathrm{mg} / \mathrm{L}$ could meet the national discharge standard of China. The detailed following conclusions can be drawn as follows:

(1) Ammonia removal efficiency increased with the ozone flow rate increased when ozone flow rate was $\leq 1 \mathrm{~L} / \mathrm{min}$, while the ammonia removal efficiency decreased with increasing of ozone flow rate when ozone flow rate was $\geq 1 \mathrm{~L} / \mathrm{min}$; the higher of the initial $\mathrm{pH}$, the higher of the ammonia nitrogen removal efficiency. However, too much acid would be needed to neutralize the excessive alkalis if the initial $\mathrm{pH}>11$; at the optimum conditions of $1 \mathrm{~L} / \mathrm{min}$ ozone flow rate and initial $\mathrm{pH} 11$, ammonia removal efficiency could reach $59.32 \%$ and $\mathrm{pH}$ reduced to 6.63 after

$120 \mathrm{~min}$ by the primary ozone oxidation, and the efficiency could reach $85 \%$ after the second stage of ozone oxidation, which would meet the discharge standard of China.

(2) During the ozonization of ammonia nitrogen, there is a certain contribution to ammonia removal by the flow stripping, but ozone oxidation predominates the removal reaction.

(3) The removal mechanism of ammonia nitrogen might be that ammonia nitrogen was mainly transformed into $\mathrm{NO}_{3}{ }^{-}-\mathrm{N}$, less into $\mathrm{NO}_{2}{ }^{-}-\mathrm{N}$, not into $\mathrm{N}_{2}$.

\section{Acknowledgments}

This work was supported by the National Science and Technology Support Program (2012BAC11B07); Ministry of Education Program for New Century Excellent Talents (NCET-10-0183); "Gan Po excellence 555 project" talents training plan; training program for the leader of main science and technology in Jiangxi Province (2010DD01200); Natural science fund project in Jiangxi Province 
(20122BAB203027). Moreover, the authors extend special thanks to the team of Xu Zhenghe professors for their continuous support and help with the experiment of this article.

\section{Author Contributions}

Xianping Luo presented the original idea for the study. Nana Zhou, Caigui Luo, and Chensheng Jian carried out the experiment, analyzed the data, and drafted the manuscript. Qun Yan and Chunying Wang were scientific supervisors of all processes including writing. All authors have read and approved the final manuscript.

\section{Conflicts of Interest}

The authors declare no conflict of interest.

\section{References}

1. Xiao, Y.F.; Feng, Z.Y.; Hu, G.H.; Huang, L.; Huang, X.W.; Chen, Y.Y.; Li, M.L. Leaching and mass transfer characteristics of elements from ion-adsorption type rare earth ore. Rare Met. 2015, 34, 357-365.

2. Juan, M.G.; Lorna, G.; Ramón, M.; Juan, M.L. Nitrification of waste waters from fish-meal factories. Water SA 1998, 24, 245-249.

3. Udeh, P.J. A Guide to Healthy Drinking Water; iUniverse: Bloomington, IN, USA, 2004.

4. Graham, D.W.; Knapp, C.W.; Vleck, E.S.; Bloor, K.; Lane, T.B.; Graham, C.E. Experimental demonstration of chaotic instability in biological nitrification. ISME J. 2007, 1, 385-393.

5. Mahamudur, I.; Rajkishore, P. Synthesis and physicochemical characterization of $\mathrm{Zn} / \mathrm{Al}$ chloride layered double hydroxide and evaluation of its nitrate removal efficiency. Desalination 2010, 256, $120-128$.

6. Yang, H.; Cheng, H. Controlling nitrite level in drinking water by chlorination and chloramination. Sep. Purif. Technol. 2007, 56, 392-396.

7. Guo, Z.; Zheng, Z.; Gu, C.; Zheng, Y. Gamma irradiation-induced removal of low-concentration nitrite in aqueous solution. Radiat. Phys. Chem. 2008, 77, 702-707.

8. Markou, G.; Vandamme, D.; Muylaert, K. Using natural zeolite for ammonia sorption from wastewater and as nitrogen releaser for the cultivation of Arthrospira platensis. Bioresour. Tchnol. 2014, 155, 373-378.

9. Wang, H.; Zhou, K.G. The research development on the treatment of ammonia-nitrogen wastewater. Ind. Saf. Environ. Prot. 2006, 32, 7-9. (In Chinese)

10. Li, B.; Zhao, J.Y.; Lu, J.F. Numerical study of the simultaneous oxidation of $\mathrm{NO}$ and $\mathrm{SO}_{2}$ by ozone. Int. J. Environ. Res. Public Health 2015, 12, 1595-1611.

11. Ishizuka, Y.; Tokumura, M.; Mizukoshi, A.; Miyuki Noguchi, M.; Yanagisawa, Y. Measurement of Secondary Products during oxidation reactions of terpenes and ozone based on the Prt-MS analysis: Effects of coexistent carbonyl compounds. Int. J. Environ. Res. Public Health 2010, 7, 3853-3870. 
12. Turhan, K.; Turgut, Z. Decolorization of direct dye in textile wastewater by ozonization in a semi-batch bubble column reactor. Desalination 2009, 242, 256-263.

13. Domeno, C.; Rodriguex-Lafuente, A.; Martos, J.M.; Bilbao, R. VOC removal and deodorization of effluent gases from an industrial plant by photo-oxidation, chemical oxidation, and ozonization. Environ. Sci. Technol. 2010, 44, 2585-2591.

14. Park, J.C. The removal of tin from ITO-scrap via ozonization. Bull. Korean Chem. Soc. 2009, 30, 3141-3142.

15. Khuntia, S.; Majumder, S.K.; Ghosh, P. Removal of ammonia from water by ozone microbubbles. Ind. Eng. Chem. Res. 2012, 52, 318-326.

16. Tanaka, J.; Matsumura, M. Application of ozone treatment for ammonia removal in spent brine. Adv. Environ. Res. 2003, 7, 835-845.

17. Schroeder, J.P.; Croot, P.L.; von Dewitz, B.; Waller, U.; Hanel, R. Potential and limitations of ozone for the removal of ammonia, nitrite, and yellow substances in marine recirculating aquaculture systems. Aquac. Eng. 2011, 45, 35-41.

18. Bogoczek, R.; Kociołek-Balawejder, E.; Stanisławska, E. A macromolecular oxidant, the N,N-dichlorosulfonamide for removal of residual nitrites from aqueous media. React. Funct. Polym. 2006, 66, 609-617.

19. Ministry of Environmental Protection. Water Quality-Determination of Ammonia NitrogenNessler's Reagent Spectrophotometry, 1st ed.; China Environmental Science Press: Beijing, China, 2010; pp. 1-4. (In Chinese).

20. State Environmental Protection Administration. Water Quality-Determination of Nitrogen (Nitrite)-Spectrophotometric Method, 1st ed.; China Standard Press: Beijing, China, 1987; pp. 1-4. (In Chinese).

21. State Environmental Protection Administration. Water Quality-Determination of Nitrate-Spectrophotometric Method with Phenol Disulfonic Acid, 1st ed.; China Standard Press: Beijing, China, 1987; pp. 1-4. (In Chinese).

22. Ministry of Environmental Protection. Water Quality-Determination of Total Nitrogen-Alkaline Potassium Persulfate Digestion UV Spectrophotometric Method, 1st ed.; China Environmental Science Press: Beijing, China, 2012; pp. 1-8. (In Chinese).

23. Ministry of Housing and Urban-Rural Development of People's Republic of China. Ozone Generator for Water and Wastewater Treatment, 1st ed.; China Standard Press: Beijing, China, 2010; p. 8. (In Chinese).

24. Sun, D.C. Research on Disposing Wastewater with High Concentration Ammonia Nitrogen Using Ozone. Master's Thesis, Qingdao Technological University, Qingdao, China, 2009. (In Chinese)

25. Hoigné, J.; Bader, H.; Haag, W.R.; Staehelin, J. Rate constants of reactions of ozone with organic and inorganic compounds in water-III: Inorganic compounds and radicals. Water Res. 1985, 19, 993-1004.

26. Wu, X.G. Degradation of Some Organic Pollutants Using a Combination Teehnique of Ozone-Activated Carbon and Advanced Oxidation. Ph.D. Thesis, Graduate University of Chinese Academy of Science, Beijing, China, 2007. (In Chinese). 
27. Zhong, L.; Kuo, C.H. Kinetics and mechanism of ozone with hydrogen peroxide. J. South China Univ. Technol. (Nat. Sci.) 1997, 25, 50-54. (In Chinese).

28. Zhong, L.; Kuo, C.H. Investigation on wet-ozonization degradation of ammonia nitrogen. China Water Wastewater 2000, 16, 15-16. (In Chinese).

(C) 2015 by the authors; licensee MDPI, Basel, Switzerland. This article is an open access article distributed under the terms and conditions of the Creative Commons Attribution license (http://creativecommons.org/licenses/by/4.0/). 